\title{
Eccrine hidrocystoma of the eyelid
}

\begin{abstract}
Aim To report on the clinical features of eccrine hidrocystoma involving the eyelid. Methods Data on a series of consecutive patients with histopathologically confirmed diagnosis were reviewed.

Results Among 34 patients, 69 tumours were identified. The mean age at diagnosis was 59 years (range 39-91 years). The majority (71\%) of patients had only a single tumour. The tumours appeared as a small (median size $=1 \mathrm{~mm}$ ) clear cystic lesion with $87 \%$ located near the eyelid margin.

Conclusions The eccrine hidrocystoma is a benign small cystic tumour that characteristically occurs close to but does not involve the eyelid margin.

Eye (2005) 19, 77-79. doi:10.1038/sj.eye.6701404

Published online 18 June 2004
\end{abstract}

Keywords: benign tumors; eyelid; sweat gland; eccrine; hidrocystoma

\section{Introduction}

Eyelid tumours can be clinically classified as cystic, nodular, ulcerative, papillomatous, or infiltrating. Various types of sebaceous glands (Zeis and Meibomian) and sweat glands (eccrine and apocrine) are present in the eyelid and each type of gland can develop cystic pathology.

Eccrine sweat glands are widely distributed in the body and each gland consists of a single duct with a coiled deeper component. ${ }^{1}$ By contrast, the apocrine sweat glands are limited to the special regions such as axilla, nipple, external ear, external genitalia, and the eyelids. ${ }^{1}$ The apocrine glands are larger than the eccrine glands, are more numerous in the lower eyelid, and their ductal openings are closely associated with eyelashes. ${ }^{2}$

Eccrine hidrocystoma is a cutaneous lesion that occurs predominantly on the face. .,4 $^{3,4}$ Clinical manifestations include either multiple
AD Singh', L McCloskey², MA Parsons ${ }^{3}$ and

DN Slater ${ }^{4}$

(Robinson type) ${ }^{5}$ or solitary lesions (Smith and Chernosky type). ${ }^{6}$ Eccrine hidrocystoma is believed to represent cystic dilatation of intradermal sweat ducts rather than a neoplastic proliferation. ${ }^{6}$ Although cases of rare sweat gland tumours of the eyelids have been reported previously, ${ }^{7}$ there is limited information about the clinical features of eccrine hidrocystoma involving the eyelids. In this report, we present the clinical features of 34 consecutive patients with histopathologically proven eccrine hidrocystoma, so as to facilitate improvement in clinical recognition.

\section{Materials and methods}

Data from all patients with a histopathologically proven diagnosis of eccrine hidrocystoma treated at the Department of Ophthalmology, Royal Hallamshire Hospital, Sheffield between March 1994 and March 2002 were retrospectively collected. During this period, approximately 1000 eyelid biopsies were performed. Clinical records, drawings, external photographs (where available), and histopathology of all cases were reviewed. In addition to basic demographic data, detailed ophthalmic clinical features such as extent of involvement (unilateral/bilateral; upper/lower eyelid), number (per patient), distribution (medial/central/lateral/diffuse), size (largest dimension), and colour (clear/brown/blue) of the tumour was also investigated. The location of the tumour was classified as marginal (epicentre of the lesion within $4 \mathrm{~mm}$ of the eyelid margin), palpebral (epicentre of the lesion more than $4 \mathrm{~mm}$ of the eyelid margin and up to the paplebral sulcus) and orbital (epicenter of the lesion beyond the palberal sulcus).

\section{Results}

Among 34 patients (male patients $=19$; female patients $=15), 69$ tumours involving 38 eyes (right eye only $=16$ patients; left eye only $=14$ patients; and both eyes = four patients) were
${ }^{1}$ Department of Ophthalmic Oncology, Cole Eye Institute Cleveland Clinic Foundation Cleveland, USA

${ }^{2}$ Department of Ophthalmology Royal Hallamshire Hospital Sheffield, UK

${ }^{3}$ Ophthalmic Sciences Unit University of Sheffield, UK

${ }^{4}$ Department of Histopathology Royal Hallamshire Hospital Sheffield, UK

Correspondence: $A D$ Singh, $M D$ Department of Ophthalmic Oncology

Cole Eye Institute (i3-129)

Cleveland Clinic Foundation 9500 Euclid Avenue

Cleveland, USA

Tel: + 2164459479

Fax: + 2164452226

E-mail: SINGHA@

CCF.ORG

Received: 27 June 2003 Accepted: 10 October 2003 Published online: 18 June 2004 
identified and they formed the basis of the present study (Table 1). The mean age at diagnosis was 59 years (range 39-91 years). Most of the patients (71\%) had only one tumour, nine patients $(26 \%)$ had up to 10 tumours, and only one patient had more than 10 tumours. Of the 69 tumours, about one-third (22 of 69) involved the lower eyelid and two-thirds (47 of 69) involved the upper eyelid. The tumours were predominantly $(87 \%)$ near the eyelid margin and tended to be along the medial (36\%) or lateral (32\%) aspects (Figure 1). Almost all (97\%) tumours were less than $10 \mathrm{~mm}$ in size with the vast majority $(75 \%)$ of them less than $5 \mathrm{~mm}$ in maximal diameter. About onethird of all tumors were $1 \mathrm{~mm}$ or less in size. The mean tumour size was $4 \mathrm{~mm}$. The tumours appeared as a clear cyst $(90 \%)$ with brown pigmentation observed in only six tumors (9\%). All tumors were excised completely without recurrence.

Table 1 Clinical findings in 34 patients with eccrine hidrocytoma of the eyelid

\begin{tabular}{|c|c|c|c|}
\hline Category & Numbers & Subcategory & Numbers \\
\hline \multirow[t]{2}{*}{ Patients } & 34 & Males & 19 \\
\hline & & Females & 15 \\
\hline \multirow[t]{3}{*}{ Eyes } & 38 & Right & 16 \\
\hline & & Left & 14 \\
\hline & & Bilateral & 4 \\
\hline \multirow[t]{26}{*}{ Tumours } & 69 & \multicolumn{2}{|l|}{ Number of tumours per patient } \\
\hline & & 1 & 24 \\
\hline & & 2 & 6 \\
\hline & & $3-10$ & 3 \\
\hline & & $\geq 10$ & 1 \\
\hline & & \multicolumn{2}{|l|}{ Eyelid } \\
\hline & & Lower & 22 \\
\hline & & Upper & 47 \\
\hline & & \multicolumn{2}{|l|}{ Location } \\
\hline & & Marginal $^{\mathrm{a}}$ & 60 \\
\hline & & Palpebral & 5 \\
\hline & & Orbital & 4 \\
\hline & & \multicolumn{2}{|l|}{ Distribution } \\
\hline & & Medial & 25 \\
\hline & & Central & 2 \\
\hline & & Lateral & 22 \\
\hline & & Diffuse & 20 \\
\hline & & \multicolumn{2}{|l|}{ Size $(\mathrm{mm})$} \\
\hline & & $\leq 1$ & 21 \\
\hline & & $2-5$ & 31 \\
\hline & & $6-10$ & 14 \\
\hline & & $\geq 11$ & 3 \\
\hline & & \multicolumn{2}{|l|}{ Colour } \\
\hline & & Clear & 62 \\
\hline & & Brown & 6 \\
\hline & & Blue & 1 \\
\hline
\end{tabular}

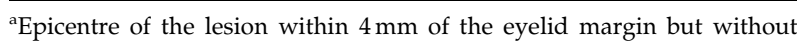
direct involvement of the eyelid margin.

\section{Discussion}

Benign adnexal lesions of the eyelids are much more frequent than the malignant lesions. ${ }^{8,9}$ In a series of 864 eyelid lesions that were biopsied, $82 \%$ were benign. ${ }^{8}$ The frequency of eccrine hidrocystoma is not known. In a series of 130 sweat gland lesions of the eyelids seen at Armed Forces Institute of Pathology, Washington, DC, hidrocystoma represented $22 \%$ of all cases. ${ }^{10}$
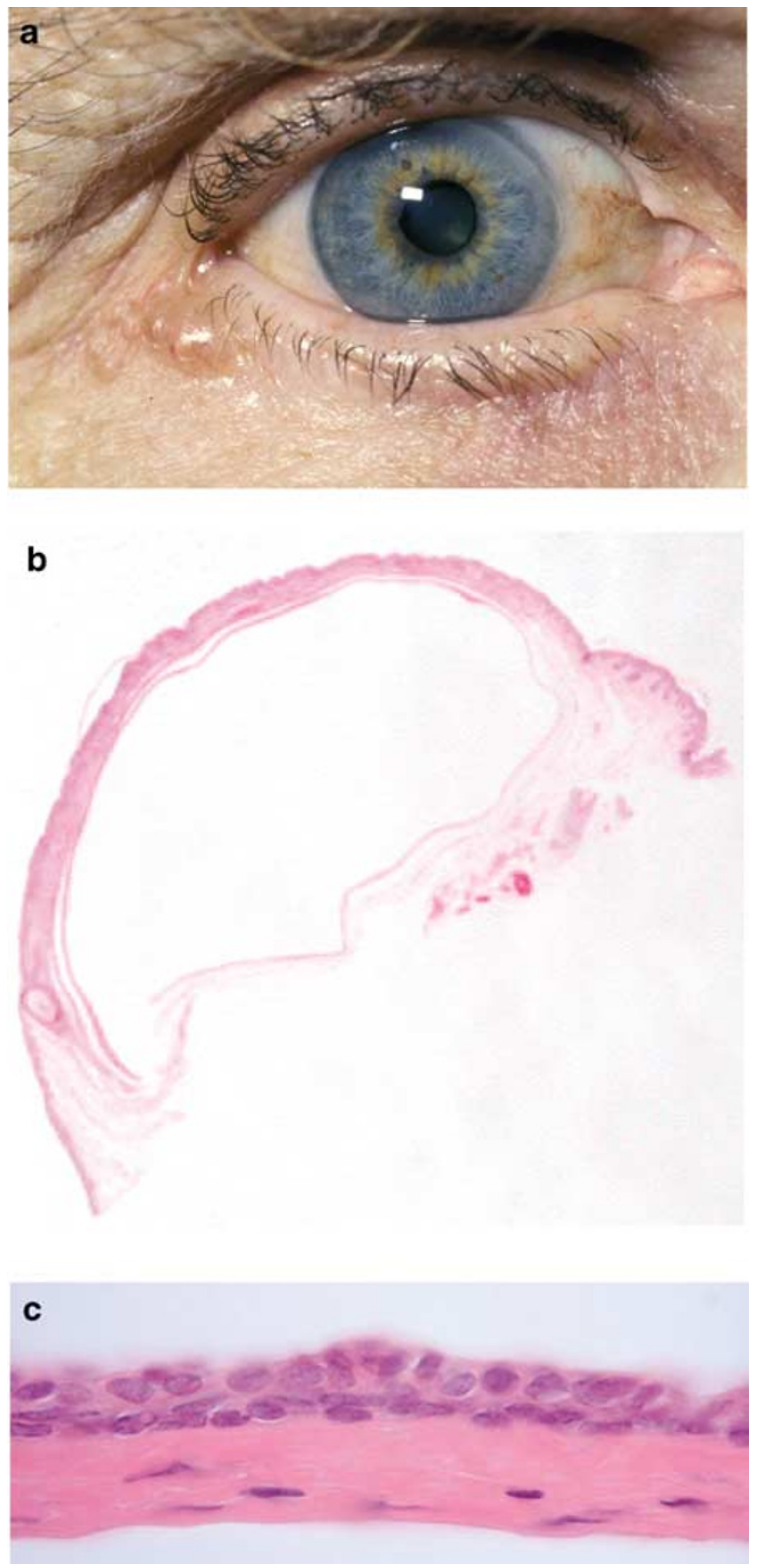

Figure 1 (a) External photograph of eccrine hidrocystoma. Note the gap between the tumour and the eyelid margin. (b) Photomicrograph showing eccrine hidrocystoma. Note absence of papillary projections into the cavity (H\&E low power). (c) The lining cuboidal epithelium is double layered and the cells lack decapitation (H\&E, high power). 
A clinicopathological series of 55 sweat gland tumours involving the eyelids did not include any cases of eccrine hidrocytoma. ${ }^{7}$ Our series of 34 patients with eccrine hidrocystoma represents less than $5 \%$ of all eyelid biopsies performed during the study period.

The accuracy of clinically suspecting a malignant eyelid tumour is reported in the range of $90 \% .^{8,9}$ However, no such figures are available when evaluating benign eyelid lesions. The differential diagnosis of eccrine hidrocystoma includes other cystic lesions of the eyelid such as follicular derived cysts, epidermal inclusion cyst, haemangioma, lymphangioma, apocrine hidrocystoma, and eccrine acrospiroma. Eccrine hidrocystoma can be differentiated clinically from the apocrine hidrocystoma (cyst of Moll) ${ }^{11}$ by the location of the tumour in relation to the eyelid margin. In contrast to apocrine hidrocystoma, the eccrine hidrocystoma does not involve the eyelid margin. This is due to the fact that the eccrine sweat glands are distributed throughout the eyelid skin and are not confined to the eyelid margin unlike the apocrine glands. In addition, the apocrine hidrocystoma tend to have bluish colour with yellow apical deposits. ${ }^{12}$

Our observations indicate that a typical eccrine hidrocystoma of the eyelid manifests in an adult as a solitary clear cystic lesion although cases with simultaneous bilateral involvement have also been reported. ${ }^{13}$ The tumour is usually located along the medial or lateral aspect of the eyelid. The eccrine hidrocystoma characteristically occurs close to but does not involve the eyelid margin. It is rare for eccrine hidrocystoma of the eyelid to be larger than $10 \mathrm{~mm}$ and on average they measure $4 \mathrm{~mm}$ in the largest dimension. These set of findings should help in the clinical recognition of eccrine hidrocystoma.

\section{References}

1 Warwick R, Williams PL. Gray's Anatomy, 35th ed. Longman Group Ltd: Edinburgh, 1973, pp 1168-1169.

2 Warwick R. Eugene Wolf's Anatomy of the End Orbit, 7th ed. H.K. Lewis \& Co. Ltd: London, 1976, pp 195-197.

3 Spurling LC, Sakas EL. Eccrine hydrocystomas. J Am Acad Dermatol 1982; 7: 763-770.

4 Alfadley A, Al Aboud K, Tulba A, Mourad MM. Multiple eccrine hidrocystomas of the face. Int J Dermatol 2001; 40: 125-129.

5 Robinson AR. Hidrocystoma. J Cutan Genitourin Dis 1893; 11: 293-303.

6 Smith JD, Chernosky ME. Hidrocystomas. Arch Dermatol 1973; 108: 676-679.

7 Ni C, Dryja TP, Albert DM. Sweat gland tumor in the eyelids: a clinicopathological analysis of 55 cases. Int Ophthalmol Clin 1981; 23: 1-22.

8 Kersten RC, Ewing-Chow D, Kulwin DR, Gallon M. Accuracy of clinical diagnosis of cutaneous eyelid lesions. Ophthalmology 1997; 104: 479-484.

9 Margo CE. Eyelid tumors: accuracy of clinical diagnosis. Am J Ophthalmol 1999; 128: 635-636.

10 McLean IW, Burnier MN, Zimmerman LE, Jakobiec FA Tumors of the Eye and Ocular Adnexa. Armed Forces Institute of Pathology: Washington, DC, 1993, pp 9-11.

11 Smith JD, Chernosky ME. Apocrine hidrocystoma (cystadenoma). Arch Dermatol 1974; 109: 700-702.

12 Sacks E, Jakobiec FA, McMillan R, Fraunfelder F, Iwamoto T. Multiple bilateral apocrine cystadenomas of the lower eyelids. Light and electron microscopic studies. Ophthalmology 1987; 94: 65-71.

13 Yasaka N, Iozumi K, Nashiro K, Tsuchida T, Seki Y, Furue M et al. Bilateral periorbital eccrine hidrocystoma. J Dermatol 1994; 21: 490-493. 